\title{
Multipl Skleroz Tanılı Hastalarda Algılanan Yorgunluğun Aktivite-Rol Yeterliliği ile İlişkisi
}

The Relationship Between the Perceived Fatigue and Occupational Competence in Patients with Multiple Sclerosis

\author{
Serkan PEKÇETIN ${ }^{1}$, Damla Ece IRMAK ${ }^{2}$, Özgü INAL ${ }^{3}$, Hülya ÖZKAN ${ }^{4}$, Sezgin \\ KEHAYA ${ }^{4}$, Hülya KAYIHAN ${ }^{5}$ \\ ${ }_{1}^{1}$ Dr. Öğr. Üyesi, Sağlık Bilimleri Üniversitesi, Gülhane Sağlık Bilimleri Fakültesi, Ergoterapi Bölümü, Ankara \\ ${ }^{2}$ Ergoterapist, Damla Ece Irmak, Damla Danışmanlık, Edirne \\ ${ }^{3}$ Dr. Öğr. Üyesi. Trakya Üniversitesi, Sağlık Bilimleri Fakültesi, Ergoterapi Bölümü, Edirne \\ ${ }^{4}$ Dr. Öğr. Üyesi, Trakya Üniversitesi, Tıp Fakültesi, Nöroloji Anabilim Dalı, Edirne \\ ${ }^{5}$ Prof. Dr, Hacettepe Üniversitesi, Sağlık Bilimleri Fakültesi, Ergoterapi Bölümü, Ankara
}

\section{öz}

Amaç: Bu çalışma Multipl Skleroz (MS) tanılı hastalarda yorgunluk ile aktivite-rol yeterliliği ve önemi arasındaki ilişkiyi incelemek amacıyla gerçekleştirildi. Gereç ve Yöntem: Çalışma, Trakya Üniversitesi Hastanesinde Şubat-Haziran 2018 tarihleri arasında 26 MS hastası ile gerçekleştirildi. Bireylerin, engellilik durumları Genişletilmiş Özürlülük Durum Ölçeği (GÖDÖ), yorgunluk düzeyleri Yorgunluk Şiddet Ölçeği (YŞÖ), aktivite-rol yeterlilikleri ile bu yeterliliklere verilen önem düzeyi Aktivite Öz-Değerlendirme Ölçeği (AÖDÖ) ile değerlendirildi. Sonuçlar: Kişilerin yorgunluk düzeyi ile engellilik durumları arasında pozitif yönde orta düzeyde, yorgunluk düzeyi ile aktivite-rol yeterliliği negatif yönde orta düzeyde istatistiksel ilişki saptandı $(p<0,05)$. Kişilerin yorgunluk düzeyi ve engellilik durumları ile aktivite-rol önemi arasında istatistiksel olarak ilişki saptanmadı $(p>0,05)$. Tartışma: Aktivite-rol yeterlilik düzeyini arttırmak ergoterapistlerin rehabilitasyon hedeflerinden biridir. Bu bağlamda, MS tanılı hastaların günlük yaşamdaki fonksiyonelliğine ve aktivite-rol yeterliliğine yönelik müdahaleler planlanırken, bireyin yorgunluk seviyesi dikkate alınmalıdır.

Anahtar Kelimeler: Ergoterapi; Multipl Skleroz; Yorgunluk

\section{ABSTRACT}

Purpose: This study was conducted to investigate the relationship between fatigue and occupational competence and its importance in patients diagnosed with Multiple Sclerosis (MS). Material and Methods: This study was carried out in Trakya University Hospital between February and June 2018 with 26 MS patients. Disability status was evaluated with Expanded Disability Status Scale (EDSS), fatigue level was evaluated with Fatigue Severity Scale (FSS) and occupational competence and the importance given to it were evaluated with Occupational Self Assessment (OSA). Results: A moderate positive correlation was found between fatigue level and disability status of individuals; a moderate negative correlation was found between fatigue level and occupational competence $(p<0.05)$. No statistically significant relationship was found between fatigue level and disability status and the importance given to occupational competence ( $p>0.05$ ). Discussion: Increasing the occupational competence level is one of the rehabilitation targets of occupational therapists. For this reason, when planning interventions for the functionality and occupational competence of people with MS in daily life, fatigue severity which may be a factor should be considered.

Key Words: Occupational therapy; Multiple Sclerosis; Fatigue 
Multipl Skleroz (MS), merkezi sinir sisteminin otoimmün demiyalinizan kronik bir hastalığıdır. Genellikle 20 ile 40 yaş arası bireylerde görülür (Eraksoy ve Akman, 2011). Kadınlarda görülme oranı erkeklerin yaklaşık iki katıdır. Hastalığın prevalansı 33/100000 olarak bildirilmiştir. Ancak coğrafi bölgelere göre bu oran değişmektedir (Pandit ve Kundapur, 2014). MS'te görülebilen semptomlar arasında yürüme bozuklukları, el fonksiyon kayıpları, mesane problemleri, duyu bozuklukları ve yorgunluk sayılabilir; en yaygın görülen semptom ise yorgunluktur (Fox, Bacon, Chamot ve ark., 2015).

Yorgunluk fiziksel veya zihinsel enerji eksikliği ya da halsizlik olarak tanımlanmıştır (PittionVouyovitch, Debouverie, Guillemin ve ark., 2006). MS'te yorgunluk ise, anormal yorgunluk hissi ve enerji kaybı olarak tanımlanmakta ve egzersiz sonrası sağlıklı bireylerin yaşadığı yorgunluktan farklı, alışılmadık bir durum olarak kabul edilmektedir (Khan, Amatya ve Galea 2014). MS'te yorgunluğun mekanizması tam olarak açıklanamamıştır ve öznel bir deneyim olması nedeniyle de etkili müdahale stratejileri oluşturulamamıştır (Braley ve Chervin, 2010). Yorgunluğun, MS tanılı hastaların günlük yaşam aktivitelerini yaparken problemlere neden olduğu ve bu bireylerin istihdama katılmalarını olumsuz etkilediği bildirilmiştir (Ward ve Robinson, 2008). Yorgunluğun aktivite ve rol katılımına etkilerinden dolayı ergoterapi alanında çalışan meslek elemanlarının müdahale ve değerlendirmelerine intiyaç olduğu bilinmektedir (Maitra, Hall, Kalish ve ark., 2010).

Ergoterapi modellerinden olan İnsan Aktivite Rol Modeli (Model of Human Occupation, $\mathrm{MOHO}$ ); aktivite-rol yeterliliğini, kişinin kimliğini yansıtan bir aktivite performans paternini sürdürebilme derecesi olarak tanımlamıştır. Diğer bir deyişle kişinin aktiviterol performansı ile ilgili kendi algısıdır. Aktivite-rol önemi ise, kişinin gerçekleştirdiği bu aktivite-rol performanslarının hangilerinin en önemli olduğuna dair kişinin algısıdır. Aktivite-rol yeterlilik ve önem düzeylerinin belirlenmesi ile kişinin bir engel ya da hastalıktan dolayı aktivite-rol katılımının hangi düzeyde etkilendiğini kişi kendi bakış açısından değerlendirecektir. Aynı zamanda terapist, bireyin aktivite-rol katılımındaki etkilenmeyi MOHO'nun kavramsal çerçevesini oluşturan irade, alışkanlık ve performans kapasitesi kavramlarını ve bunların birbirleriyle olan ilişkisi çerçevesinde tanımlayabilecektir (Baron, 2006).

MS tanılı hastalarda yorgunluğun; bireyin engel durumu, kişilik özellikleri, yaşam kalitesi, uyku problemleri, günlük yaşam aktiviteleri, bilişsel ve psikolojik özellikleri gibi değişkenler ile ilişkisi incelenmiştir (Ben Ari, Johansson, Ytterberg ve ark., 2014; Fernández-Muñoz, Morón-Verdasco, CigaránMéndez ve ark., 2015; Tabrizi ve Radfar, 2015). Ancak MS tanılı hastalarda görülen yorgunluğun aktivite-rol yeterliliği ve önemi ile ilişkisini MOHO'nun kavramsal çerçevesinden inceleyen bir çalışmaya rastlanmamıştır. Halbuki, MOHO'nun ergoterapistlerin klinik uygulamalarda en fazla kullandıkları model olduğu literatürde gösterilmiştir (Lee, Taylor, Kielhofner ve ark., 2008). Dolayısı ile bu çalışma, MS tanılı hastalardaki yorgunluk düzeyi ile aktivite-rol yeterliliği ve önemi arasındaki ilişkiyi incelemek amacı ile gerçekleştirilmiştir.

\section{GEREÇ VE YÖNTEM}

Çalışma, Trakya Üniversitesi Hastanesinde ŞubatHaziran 2018 tarihleri arasında gerçekleştirildi. Çalışma için Trakya Üniversitesi Etik Kurulu'ndan etik kurul onayı alındı (TÜTF-BAEK 2018/38). Çalışmaya katılmaya gönüllü olan bireylere yazılı onam formu imzalatıldı.

\section{Katılımcılar}

Nöroloji hekimi tarafından McDonald tanı kriterleri ile MS tanısı konulan hastalar çalışmaya dahil edildi. MS dışında nörolojik hastalığı olanlar, kalp hastaları, kanser hastaları, son bir ay içerisinde geçirilmiş atak öyküsü bulunan ve bilişsel problemi olan MS tanılı hastalar çalışmaya dahil edilmedi.

\section{Ölçekler}

\section{Genişletilmiş Özürlülük Durum Ölçeği (GÖDÖ)}

Bireylerin, engellilik durumunu belirlemek için GÖDÖ skorları klinik takiplerini gerçekleştiren nöroloji doktoru tarafından değerlendirildi. Bu skala ile 8 fonksiyonel sistemdeki (piramidal, serebellar, beyin sapı, duyu, mesane ve bağırsak, görsel, serebral) yetersizlik ölçülmektedir. Her bir sistem 0 ile 6 arasında puanlanmaktadır. Sıfır normal nörolojik muayeneyi gösterirken, 10 MS'e bağlı ölümü temsil etmektedir (Kurtzke, 1983).

\section{Yorgunluk Şiddet Ölçeği (YŞÖ)}

Bireylerin yorgunluk düzeylerinin değerlendirmesinde Türkçe geçerlik ve güvenirliği gösterilmiş olan YŞÖ uygulandı. Bu ölçek dokuz maddeden oluşmaktadır. Her madde 1 ile 7 arasında puanlanır ve toplam puan azaldıkça, yorgunluk da azalır (Armutlu, Korkmaz, Keser ve ark., 2007).

\section{Aktivite Öz-Değerlendirme Ölçeği (AÖDÖ)}

AÖDÖ, MOHO temelli ve kişi merkezli bir değerlendirme aracıdır. Bireylerin aktivite-rol yeterliliğiyle ilgili algısını ve aktivite-rollere verdiği 
önemi değerlendirmek amacıyla kullanılan ölçek, 21 maddeden oluşmaktadır. Her bir madde için 4'lü likert skalada birey aktivite yeterliliğini (1 = çok problem var $4=$ çok iyi) ve önemini ( $1=$ çok önemli değil 4 = en önemlisi) ayrı ayrı puanlamaktadır. Elde edilen puanlar toplanarak yeterlilik ile önem olmak üzere iki ayrı toplam puan elde edilir. Bu puanlar ölçeğin uygulama kılavuzunda yer alan yöntem ile 0100 arasındaki puanlara dönüştürülür. Toplam puan arttıkça aktivite öz-yeterlilik ve önemi artar. Ölçeğin, Türkçe geçerliliği gösterilmiştir (Pekçetin, Salar, İnal ve ark., 2018).

\section{Istatistiksel analiz}

Verilerin istatistiksel değerlendirmesi, SPSS 22.0 istatistik programı kullanılarak yapıldı. Tanımlayıcı verilere ilişkin nitel veriler, sayı $(n)$ ve yüzde (\%) olarak verildi ve nicel verilerin aritmetik ortalama $(X)$ veya medyan, standart sapma (SS) değerleri hesaplandı. Elde edilen ölçümlere ait tanımlayıcı değerler hesaplanıp tablolar halinde verildi. Sayısal özelliklerin her bir grupta normal dağılım gösterip göstermediği Shapiro Wilk ve Kolmogorov-Smirnov testleri ile incelendi. Verilerin normal dağılım göstermediği bulundu ve veriler arasındaki ilişki
Spearman korelasyon katsayısı hesaplandı. $r=0-$ 0,19 ilişki yok; 0,20-0,39 zayıf ilişki; 0,40-0,69 orta ilişki; 0,70-0,89 kuvvetli ilişki; 0,90-1,00 çok kuvvetli ilişki olarak kabul edildi. İstatistik anlamlılık düzeyi $p<0,05$ alındı. Çalışmanın güç analizi, G Power 3.0.10 programı kullanılarak hesaplandı ve çalışmanın gücü $\% 90$ olarak bulundu.

\section{SONUÇLAR}

Çalışmaya yaş ortalaması $40.46 \pm 10.14$ yıl olan 26 birey (5 erkek, 21 kadın) katıldı. Çalışmaya katılan bireylerin \%38,5'i ilköğretim, \%34,6'sı lise, \%26,9'u üniversite mezunu idi. Bireylerin \%76,9'u evli, $\% 23,1$ 'i bekardı.

Bireylerin GÖDÖ puan ortalaması 2,38 $\pm 2,17$ ve

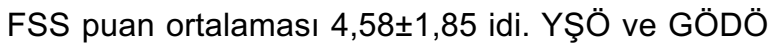
puanları arasında pozitif yönde orta düzeyde ilişki bulundu $(p<0,05)$. YŞÖ ile aktivite rol yeterlilik puanı arasında negatif yönde orta düzeyde ilişki saptandı $(p<0,05)$. YŞÖ ve GÖDÖ puanları ile aktivite önem puanı arasında istatistiksel olarak ilişki saptanmadı $(p>0,05)$ (Tablo 1). Sonuç olarak bireylerin yorgunluk düzeyleri ile engellilik durumları ve aktivite-rol yeterliliği ilişkili olduğu; ancak aktivite-rol öneminin ilişkisinin olmadığı bulunmuştur.

Tablo 1. GÖDÖ, YŞÖ, AÖDÖ yeterlilik ve önem puanları arasındaki ilişki

\begin{tabular}{|c|c|c|c|c|c|c|c|c|}
\hline & \multicolumn{2}{|c|}{$\begin{array}{l}\text { GÖDÖ } \\
(n: 26)\end{array}$} & \multicolumn{2}{|c|}{$\begin{array}{l}\text { YŞÖ } \\
\text { (n:26) }\end{array}$} & \multicolumn{2}{|c|}{$\begin{array}{l}\text { AÖDÖ Yeterlilik } \\
\qquad(n: 26)\end{array}$} & \multicolumn{2}{|c|}{$\begin{array}{l}\text { AÖDÖ Önem } \\
(n: 26)\end{array}$} \\
\hline & $r$ & $p$ & $r$ & $p$ & $r$ & $p$ & $r$ & $p$ \\
\hline GÖDÖ & - & - & ,427 & $<0,05^{\star}$ &,$- 667^{\star *}$ & $<0,01^{* *}$ &,- 180 & $>0.05$ \\
\hline YŞÖ & ,427 & $<0,05^{*}$ & - & - &,$- 400^{*}$ & $<0,05^{*}$ & -.157 & $>0.05$ \\
\hline AÖDÖ Yeterlilik &,- 667 & $<0,01^{* *}$ &,$- 400^{*}$ & $<0,05^{*}$ & - & - & .271 & $>0.05$ \\
\hline AÖDÖ Önem &,- 180 & $>0,05$ &,- 157 & $>0,05$ & ,271 & $>0,05$ & - & - \\
\hline
\end{tabular}

Kısaltmalar: GÖDÖ: Genişletilmiş Özür Durum Anketi, YŞÖ: Yorgunluk Şiddet Ölçeği, AÖDÖ: Aktivite Öz Değerlendirme Ölçeği, * $p<0.05,{ }^{* *}<0.01$

\section{TARTIŞMA}

MS tanılı hastaların algıladıkları yorgunluk ile aktivite-rol yeterlilik ve önemi arasındaki ilişkiyi incelemek amacıyla gerçekleştirilen bu çalışmada hastaların yorgunluk düzeyleri artıkça aktivite-rol yeterliliklerinin azaldığı, yorgunluk ve aktivite-rol öneminin ise ilişkili olmadığı bulunmuştur.

Literatürde MS tanılı hastaların sağlıklı bireylere göre temel ve yardımcı günlük yaşam aktivitelerinde daha fazla problem yaşadıklarını gösteren pek çok çalışma bulunmaktadır (Kitis, Altug, Cavlak ve ark., 2008; Ma, Wu, Yeh ve ark., 2017; Papathanasiou, Messinis, Zampakis ve ark., 2015). Ancak, MS tanılı hastalarda yorgunluğun günlük yaşam aktivitelerine olumsuz etkisini gösteren çalışmalar az sayıdadır (Rosenblum ve Weiss, 2010). Çalışmanın sonuçları, yorgunluk ile aktivite-rol yeterliliği arasındaki ilişkiyi göstererek MS tanılı hastaların yaşamış oldukları 
olumsuz etkilerin nedenlerinden biri olabilecek, bireylerin algıladığı yorgunluk düzeyleri ile ilgili yeni bilgiler elde edilmesini sağlamıştır.

Ergoterapi alanında çalışmakta olan meslek elemanlarının yorgunluk ile ilgili müdahaleler yaptıkları bilinmektedir (Blikman, Huisstede, Kooijmans ve ark., 2013; Finlayson, Preissner, Cho ve ark., 2011; Vanage, Gilbertson ve Mathiowetz, 2003). Nitekim ülkemizde yapılan bir çalışmada, MS tanılı hastalara enerji koruma tekniklerini öğreterek bireylerin yorgunluk düzeyinde azalma ve kendine bakım, üretkenlik ve serbest zaman aktivitelerine ait performans ve memnuniyet düzeylerinde iyileşme olduğunu bildirilmiştir (Turunç ve Ekici, 2017). Bu bağlamda ergoterapi alanında çalışmakta olan meslek elemanlarının MS tanılı hastalar için gerekli müdahaleleri planlarken hastaların yorgunluk düzeylerini de göz önüne alınmasının gerekli olduğu düşünülmektedir.

Ergoterapi perspektifinde "aktivite-rol önemi" kavramının değerinin bilinmesine rağmen, bu boyut sıklıkla araştırmacılar tarafından göz ardı edilebilmektedir. Bu durum; "aktivite-rol önemi" kavramı doğası gereği hem karmaşık hem de öznel bir kavram olmasından kaynaklanmaktadır (Abdullah, Badr ve Manee, 2017). Çalışmamızda yorgunluk ve aktivitelere verilen önem arasında ilişki olmamasının, aktivite-rol öneminin karmaşık doğası ve öznel bir kavram olmasından kaynaklandığını düşünmekteyiz.

MS tanılı hastalarda çeşitli düzeylerde yeti yitimi görülebilmektedir (Hatipoglu, Kabay, Hatipoglu ve ark., 2016; Langeskov-Christensen, Feys, Baert ve ark., 2017). Yeti yitimi ile günlük yaşam aktiviteleri arasındaki ilişki araştırmacılar tarafından daha önce gösterilmiştir (Fatma ve Mollaoğlu, 2011; Pan, Lu ve Cheng, 2013). Literatürdeki sonuçlara benzer şekilde çalışmamızda engellilik durumu ile aktiviterol yeterliliği ilişkili bulunmuştur.

Çalışmamıza katılan kişilerin aktivite-rol yeterliliği ile ilgili sadece öznel değerlendirme yöntemlerinin kullanılmış olması çalışmanın limitasyonudur. İleride yapılacak çalışmalarda öznel değerlendirme yöntemlerinin objektif ölçümler ile desteklenmesi ile daha güçlü kanıtların elde edileceği düşünülmektedir.

Sonuç olarak, MS tanılı hastalarda algılanan yorgunluk ile aktivite-rol yeterliliğinin ilişkili olması nedeniyle MS tanılı hastalarda günlük yaşamdaki fonksiyonelliğine ve aktivite-rol yeterliliğine yönelik müdahalelerin, bireylerin yorgunluk seviyesinin göz önüne alınarak planlanmasının önemli olduğunu düşünülmektedir.

\section{Kaynaklar}

Abdullah, E. J., Badr, H. E., \& Manee, F. (2017). MS People's Performance and satisfaction with daily occupations: Implications for occupational therapy. OTJR (Thorofare $N$ J), 38(1), 28-37.

Armutlu, K., Korkmaz, N. C., Keser, I., Sumbuloglu, V., Akbiyik, D. I., Guney, Z., et al. (2007). The validity and reliability of the Fatigue Severity Scale in Turkish multiple sclerosis patients. Int J Reh Res, 30(1), 81-85.

Baron, K. (2006). Occupational Self Assessment Version 2.2. Model of Human Occupation Clearinghouse, 5-16.

Ben Ari, E., Johansson, S., Ytterberg, C., Bergström, J., \& Von Koch, L. (2014). How are cognitive impairment, fatigue and signs of depression related to participation in daily life among persons with multiple sclerosis? Disabil Rehabil, 36(23), 2012-2018.

Blikman, L. J., Huisstede, B. M., Kooijmans, H., Stam, H. J., Bussmann, J. B., \& van Meeteren, J. (2013). Effectiveness of energy conservation treatment in reducing fatigue in multiple sclerosis: a systematic review and meta-analysis. Arch Med Rehabil, 94(7), 1360-1376.

Braley, T. J., \& Chervin, R. D. (2010). Fatigue in multiple sclerosis: mechanisms, evaluation, and treatment. Sleep, 33(8), 1061-1067.

Er F., \& Mollaoğlu, M. (2011). Disability and activities of daily living in the patients with multiple sclerosis. J Neurol Sci (Turkish), 28(2), 190-203.

Eraksoy M, Akman D.G. (2011). Merkezi sinir sisteminin myelin hastalıkları: Temel ve Klinik Bilimler Ders Kitapları, Nöroloji. İstanbul: Nobel Tıp Kitabevleri, 603-630.

Fernández-Muñoz, J., Morón-Verdasco, A., Cigarán-Méndez, M., Muñoz-Hellín, E., Pérez-de-Heredia-Torres, M., \& Fernández-de-las-Peñas, C. (2015). Disability, quality of life, personality, cognitive and psychological variables associated with fatigue in patients with multiple sclerosis. Acta Neurol Scand, 132(2), 118-124.

Finlayson, M., Preissner, K., Cho, C., \& Plow, M. (2011). Randomized trial of a teleconference-delivered fatigue management program for people with multiple sclerosis. Mult Scler, 17(9), 1130-1140.

Fox, R. J., Bacon, T. E., Chamot, E., Salter, A. R., Cutter, G. R., Kalina, J. T., et al. (2015). Prevalence of multiple sclerosis symptoms across lifespan: data from the NARCOMS Registry. Neurodegener Disabil Manag, 5(6 Suppl), 3-10.

Hatipoglu, H., Kabay, S. C., Hatipoglu, M. G., \& Ozden, H. (2016). Expanded disability status scale-based disability and dental-periodontal conditions in patients with multiple sclerosis. Med Prin Pract, 25(1), 49-55.

Khan F, Amatya B, Galea M. (2014). Management of fatigue in persons with multiple sclerosis. Front Neurol, 5(177), 114.

Kitis, A., Altug, F., Cavlak, U., \& Akdag, B. (2008). Comparison of the physical and non-physical functioning between the patients with multiple sclerosis and healthy. Neurosciences, 13(1), 29-36.

Kurtzke, J. F. (1983). Rating neurologic impairment in multiple sclerosis: an expanded disability status scale (EDSS). Neurology, 33(11), 1444-1444.

Langeskov-Christensen, D., Feys, P., Baert, I., Riemenschneider, M., Stenager, E., \& Dalgas, U. (2017). 
Performed and perceived walking ability in relation to the Expanded Disability Status Scale in persons with multiple sclerosis. J Neurol Sci, 382, 131-136.

Lee, S. W., Taylor, R., Kielhofner, G., \& Fisher, G. (2008). Theory use in practice: a national survey of therapists who use the Model of Human Occupation. Am J Occup Ther, 62(1), 106.

Ma, E., Wu, N., Yeh, W., Jones, E., \& Thomas, N. (2017). The Impact of Disability on Activities of Daily Living, Productivity and Independency in Patients with Multiple Sclerosis-Findings from a 2016 Study in Europe and the United States. Value Health, 20(9), 727-727.

Maitra, K., Hall, C., Kalish, T., Anderson, M., Dugan, E., Rehak, J., et al. (2010). Five-year retrospective study of inpatient occupational therapy outcomes for patients with multiple sclerosis. American Journal of Occupational Therapy, 64(5), 689-694.

Pan, Z., Lu, H., \& Cheng, Q. (2013). Activities of daily living and lesion position among multiple sclerosis patients by Bayes network. Neur Reg Res, 8(14), 1327-1336.

Pandit, L., \& Kundapur, R. (2014). Prevalence and patterns of demyelinating central nervous system disorders in urban Mangalore, South India. MS Jour, 20(12), 1651-1653.

Papathanasiou, A., Messinis, L., Zampakis, P., Panagiotakis, G., Gourzis, P., Georgiou, V., \& Papathanasopoulos, P. (2015). Thalamic atrophy predicts cognitive impairment in relapsing remitting multiple sclerosis. Effect on instrumental activities of daily living and employment status. J Neurol Sci, 358(1), 236-242.

Pekçetin, S., Salar, S., İnal, Ö., \& Kayıhan, H. (2018). Validity of the Turkish Occupational Self Assessment for Elderly Individuals. OTJR (Thorofare $N$ J), 38(2), 105-112.

Pittion-Vouyovitch, S., Debouverie, M., Guillemin, F., Vandenberghe, N., Anxionnat, R., \& Vespignani, H. (2006). Fatigue in multiple sclerosis is related to disability, depression and quality of life. J Neurol Sci, 243(1), 39-45.

Rosenblum, S., \& Weiss, P. L. T. (2010). Evaluating functional decline in patients with Multiple Sclerosis. Res Dev Disabil, 31(2), 577-586.

Tabrizi, F. M., \& Radfar, M. (2015). Fatigue, sleep quality, and disability in relation to quality of life in multiple sclerosis. Int J MS Care, 17(6), 268-274.

Turunç, S., \& Ekici, G. (2017). Multiple Sklerozlu Bireylerde Enerji Koruma Eğitiminin Yorgunluğa ve Aktivite Performansına Etkisi: Olgu serisi. Ergoterapi, 5(2) 79-86.

Vanage, S. M., Gilbertson, K. K., \& Mathiowetz, V. (2003). Effects of an energy conservation course on fatigue impact for persons with progressive multiple sclerosis. $A m$ J Occup Ther, 57(3), 315-323.

Ward, M., \& Robinson, K. (2008). Analysis of a fatigue management programme for people with multiple sclerosis using the canadian occupational performance measure as an outcome measure. Irish J Occ Ther, 36(1), 4-11. 
